\title{
Classification of emotions from the recognition of facial expressions applied to the prevention of secondary Alexithymia: an analysis of the state of the art
}

\section{Clasificación de las emociones a partir del reconocimiento de las expresiones faciales aplicadas a la prevención de la alexitimia secundaria: un análisis del estado del arte}

\author{
PADILLA-NAVARRO, Christian $\dagger^{*}$, ZARATE-TREJO, Carlos, KHALAF, Georges and
} FALLAVOLLITA, Pascal

Universidad Politécnica de Juventino Rosas, Mexico.

University of Ottawa, Canada.

ID $1^{\text {st }}$ Author: Christian, Padilla-Navarro / ORC ID: 0000-0002-8241-3225, CVU CONACYT ID: 427341

ID $1^{\text {st }}$ Coauthor: Carlos, Zarate-Trejo / ORC ID: 0000-0002-7417-8544

ID $2^{\text {nd }}$ Coauthor: Georges, Khalaf / ORC ID: 0000-0003-2969-6905

ID $3^{\text {rd }}$ Coauthor: Pascal, Fallavollita / ORC ID: 0000-00001-7254-8962

DOI: $10.35429 / J S T A .2020 .17 .6 .14 .17$

Received: January 10, 2020; Accepted: June 30, 2020

\begin{abstract}
Alexithymia is a condition that partially or completely deprives you of the ability to identify and describe emotions, and to show affective connotations in the actions of an individual. This problem has been taken to different research projects that seek to study its characteristics, forms of prevention, and implications, and that try to determine a measurement for the experience of an individual with this construct as well as the responses they provide to certain stimuli. Other studies that were reviewed aimed to find a connection between the responses of subjects diagnosed with alexithymia when facing a dynamic of emotional facial expressions to recognize and their assigned grade based on the Toronto Alexithymia Scale (TAS), a metric frequently used to evaluate the presence or absence of alexithymia in an individual. In this work, a review of the different articles that study this connection, as well as articles that describe the state of the art of the implementation of artificial intelligence algorithms applied to the treatment or prevention of secondary alexithymia is presented.
\end{abstract}

Alexithymia, Emotion Classification, Facial
Expressions

\section{Resumen}

La Alexitimia es una condición que priva parcial o completamente de la capacidad de identificar y describir emociones y de mostrar connotaciones afectivas en las acciones de un individuo. Este problema ha sido llevado a distintos trabajos de investigación en los que se busca estudiar sus características, formas de prevención e implicaciones, así como determinar en qué medida un individuo experimenta este constructo y las respuestas que proporciona ante ciertos estímulos. Por otra parte, los estudios que se revisaron pretenden encontrar una conexión entre la capacidad de respuesta de sujetos diagnosticados con Alexitimia, frente a una dinámica de reconocimiento de expresiones faciales emocionales, con respecto de su graduación en la Toronto Alexithymia Scale (TAS), métrica usada con frecuencia para evaluar la presencia o ausencia de Alexitimia en un individuo. En este trabajo, se presenta una revisión de los distintos artículos que estudian dicha conexión, así como el estado del arte respecto a la implementación de algoritmos de inteligencia artificial aplicados al tratamiento o prevención de Alexitimia secundaria.

Alexitimia, Clasificación de Emociones, Expresiones Faciales

Citation: PADILLA-NAVARRO, Christian, ZARATE-TREJO, Carlos, KHALAF, Georges and FALLAVOLLITA, Pascal. Classification of emotions from the recognition of facial expressions applied to the prevention of secondary Alexithymia: an analysis of the state of the art. Journal of Scientific and Technical Applications. 2020. 6-17:14-17.

\footnotetext{
* Correspondence to Author (Email: jpadilla_ptc@upjr.edu.mx)

$\dagger$ Researcher contributing as first author.
} 


\section{Introduction}

The term "alexithymia" was proposed by Peter Sifneos, a Greek psychiatrist and researcher who used it to refer to the deficit of cognitiveaffective factors belonging to the communication capacity of psychosomatic patients. Etymologically means "no words for feelings", and this condition involves the reduction or even the complete annulment of an individual's ability to understand, identify, and verbally describe emotions.

Today, there are numerous research works carried out around alexithymia focusing on the effects it has on individuals diagnosed with this condition. These works constitute an important factor for the development of treatments and measures of prevention, as well as a branching point for the writing of deeper research based on the conclusions already obtained.

\section{Alexithymic subject context}

The alexithymic patient lacks empathy for others, which severely affects their social relationships as the lack of empathy is perceived to be a negative attitude by the people around them, resulting in their detachment from the patient. In addition, they present difficulties in carrying out activities that require interpersonal interaction.

It should be noted that two important groups of alexithymia are considered to exist: primary and secondary.

Primary alexithymia refers to abnormalities at the neurobiological level and may be associated with chronic diseases. In contrast, secondary alexithymia is caused by interpersonal issues such as deep depression, repression of emotions, or even traumatic circumstances. Consequently, it is important, at least as a measure to prevent secondary alexithymia, to receive emotional education at an early age in order to identify and openly express emotions. This teaches how to regulate emotions while generating an expressive personality in the subject.
The alexithymic individual is not a creditor of complications or a malfunction of his limbic system, a section of the brain made up of the thalamus, hypothalamus and the cerebral amygdala, whose function resides in regular memory, emotions, hunger and sexual instincts.

In fact this set of organs probably did not acquire the natural relevance that it should or that due to being considered useless or a sector of vulnerability for the individual, he or she chooses to decline possible dependencies towards said system as happens in the profile of the secondary alexithymia. In retrospect, disconnection with the emotional world implies that an individual projects logical and critical reasoning in decision-making, an act based on a concrete vision of the context without considering improvised options.

Of course, the inability to interpret the emotional cues under which other people communicate is not equivalent to assuming that a subject with a high degree of alexithymia is literally emotionless. Dr. De La Serna J. Moises expresses in his work "Alexithymia, A World Without Emotions" that alexithymia is a state that reflects the consequences of other conditions, so it is not considered a disease. That is why it is referred to as a "construct" or simply a qualitative personality trait to a lesser or greater degree.

Consequently, alexithymia begins to take part in the development of psychosomatic disorders. This does not imply that alexithymia causes them but increases the probability that they will manifest. The emotional repression described by alexithymia induces in the subject a condition of "emotional somatization". Among the cases associated with this context is hypertension. Although it is true that hypertension is related to overweight, alcohol consumption and even disorders of the endocrine system, when analyzed from the psychosomatic point of view, it is concluded that it may be the manifestation of the containment of hostility in the subject.

Alexithymia generally does not represent a major problem in the professional environment, unless it requires a process of continuous interpretation and response of affective connotations. 


\section{Article selection criteria}

Technological tools, specifically based on artificial intelligence, have been important allies in the search of solutions for mental health issues, with alexithymia being one of these issues.

This research presents a deep search in the state of the art of the fundamental contributions of artificial intelligence tools focused on the detection or prevention of alexithymia, as well as research focused on the detection of facial expressions to diagnose alexithymia.

To carry out this review, only studies involving the recognition of emotional expressions from visual, textual, or acoustic sources of information that are used as stimuli to generate responses in individuals diagnosed with alexithymia, and that made use of a metric to evaluate the degree of the alexithymic condition of the subjects studied are selected. Additionally, any study or research work involving the use of artificial intelligence for the treatment, prevention, or study of alexithymia was included. Finally, these studies had to be published from 1990 onwards, either in Spanish or in English.

\section{Deficiency in the ability to recognize nonverbal emotional expressions}

Literature shows that several investigations described some factors that are typical in cases of alexithymia present even in patients who are drug users, suffering from personality disorders, depression, and panic among others.

According to the research work "Alexithymia and the Recognition of Facial Expressions of Facial Expressions of Emotion" by D. A. James, individuals with alexithymia have deficits in the perception of nonverbal emotional expressions.

The study consists of presenting a group of 131 women and 85 men a set of slides in which poses of facial expressions representing nine different emotions were shown. Each member of the group was asked to identify the emotion that the person in the photograph displayed.
Subsequently, they are evaluated using the 20-question version of the TAS test (Toronto Alexithymia Scale), with which groups of high, moderate, and low presence of alexithymia were determined. The results of the study showed that the group evaluated with a high degree of alexithymia presented a greater difficulty in identifying the expressions in the photos, in contrast to the group of lesser degree, which obtained a higher rate of success.

Similarly, the work carried out by M. S. Francisco at the University of Murcia, Spain, developed the same evaluation using TAS-20; however, contrary to the previous work, its methodology consisted in carrying out the test "Reading the mind in the eyes", which consists of matching the expression shown in the eye regions with one of four possible emotions. The results suggest that individuals with a high presence of alexithymia could develop less detailed cognitive representations of facial expressions, making it difficult to identify and assimilate their emotional meaning.

This same pattern is repeated even in works where the source of cognitive stimulation is acoustic. In the research "Cognitive biases in the recognition of emotional expressions of synthetic voice in Alexithymia", also developed by M. S. Francisco, it is explained that even when individuals are subjected to a dynamic of emotional expression to recognize based on the the tone of the voice identified, very similar results to those seen in previous evaluations are provided.

\section{Implementation of Artificial Intelligence tools applied to the detection and prevention of Alexithymia}

Artificial intelligence is a field of computer science that is responsible for the study and development of models, programs, and tools whose behaviors can be considered "intelligent". When an artificial intelligence model is developed, the algorithm that is used to train it is chosen according to the problem that is to be solved. These problems can include, but are not limited to: classification, regression, or segmentation. 
Although the mathematical bases for the integration of these algorithms were developed decades ago, this field has been growing in recent years. This in part thanks to the implementation of more powerful computer equipment and technologies dedicated to solving these types of problems, as well as their segmentation into specialized areas, of which many are yet to be explored.

This may be one of the reasons why there is a lack of work where the use of artificial intelligence is implemented in the treatment of alexithymia. However, a research paper published in 2019 at the Universidad Internacional de la Rioja and developed by A. M. Raúl describes the development of a tool that performs an evaluation to detect alexithymia using Natural Language Processing (NPL) techniques.

This work is based on an important characteristic consistent with the alexithymia already evidenced in the studies presented: the difficulty to verbally express emotions. With this work, the methodology presented consists in the construction of a model that can estimate the degree of alexithymia of a subject based on the analysis of a writing prepared by it.

Similarly, the TAS-20 metric is used as a reference to carry out the inferences of the degree of alexithymia that is presented in the individual based on NPL tools provided by IBM, Google, and Microsoft that are applied to the identification of emotional polarity in texts. Within its conclusions, it is affirmed that it is completely possible to make use of narratives as a source of data to evaluate the presence of alexithymia in a person without resorting to selfreports. A success rate of $82.4 \%$ was acquired in the pilot test applied to a group of 122 people.

\section{Conclusions}

In the current investigation, an important pattern was identified in people suffering from alexithymia regarding their ability to respond correctly to visual and acoustic cognitive stimuli. In addition, the use of artificial intelligence applied to the treatment of alexithymia is a rather scarce topic. The literature found mainly focused on the search for a method to automatically detect and evaluate the degree of alexithymia.
Finally, we determined that at this time, a research work that implements preventative measures for secondary alexithymia using an algorithm of artificial intelligence is not found in the state of the art.

\section{References}

Alonso, F. (2011). La alexitimia y su trascendencia clinica y social. Salud Mental, 481-490.

Arrabales, R. (2019). Evaluacion y Tratamiento de la Alexitimia con Herramientas de Inteligencia Artificial. Madrid, España.

Cook, R., Brewer, R., \& Shah, P. (2013). Alexithymia, Not Autism, Predicts Poor Recognition of Emotional Facial Expressions. Association For Psychological Science.

Fisch, R. Z. (2017). Alexithymia, Masked Depression and Loss in a Holocaust Survivor. BJPsych.

Grynberg, D., Chang, B., \& Corneille, O. (2012). Alexithymia and the Processing of Emotional Facial Expressions (EFEs): Systematic Review, Unanswered Questions and Further Perspectives. PLoS ONE.

Martinez, F., Fernandez, E. G., \& Sanchez, N. (2017). Recognition of Emotional Facial Expressions in Alexithymia. Studia Psychologica, 206-216.

Otero, J. (1999). Alexitimia, una revision. Asociacion Española de Neuropsiquiatria, 587596.

Parker, J., Taylor, G., \& Bagby, R. M. (1993). Alexithymia and the Recognition of Facial Expressions of Emotion. Psychoter Psychosom, 197-202.

Serna, J. M., \& de la Serna, J. M. (2015). Alexitimia, Un Mundo Sin Emociones. Zaltbommel, Países Bajos: Van Haren Publishing. 